\title{
Thermal performance of rice husk ash mixed mortar in concrete and masonry buildings
}

\author{
Kajanan Selvaranjan'1, J.C.P.H. Gamage ${ }^{2}$, G.I.P. De Silva ${ }^{3}$, \\ Vajira Attanayaka ${ }^{4}$ \\ ${ }^{1}$ Department of Civil Engineering, University of Moratuwa, Sri Lanka; \\ kajansss22@gmail.com (DD 0000-0003-3589-6065 \\ ${ }^{2}$ Department of Civil Engineering, University of Moratuwa, Sri Lanka; \\ kgamage@civil.mrt.ac.lk (iD)0000-0002-9246-8414 \\ ${ }^{3}$ Department of Materials Science and Engineering, University of Moratuwa, Sri Lanka; \\ indikagip@uom.lk iD 0000-0002-8792-3494 \\ ${ }^{4}$ Airow Solutions (Pvt) Ltd, Sri Lanka; vajira@airowsolutions.com
}

Funding: The authors acknowledge the University of Moratuwa for providing the necessary funding required for the research through Exploratory Research Grant scheme by National Research Grant (NRC/PPP/18/01).

Abstract: Rice Husk( $\mathrm{RH})$ is an agricultural waste which is produced in huge amounts from the milling process of paddy rice. Rice husk ash (RHA) is a by-product material obtained from the combustion of rice husk. The amorphous silica-rich RHA (84-90 wt\%) has a wide range of applications. This research focused on the possibility of utilizing RHA in the process of developing a mortar with low thermal conductivity to enhance the thermal comfort in concrete and masonry buildings. The thermal conductivity of mortar was determined by Lee's Disc method, and the results were compared to the data for conventional mortar as well as commercial thermal insulation materials. The results indicate a significant reduction in thermal conductivity in the mortar developed with RHA.

Keywords: rice husk ash, thermal conductivity, mortar, mechanical properties, SEM

\section{Introduction}

Concerns with sustainable waste management and recycling have become prominent in all sectors of the economy. Thus, the new approaches to energy-efficient design are the development and use of natural materials. Replacement of cement with fly ash, sawdust ash, waste ceramic, recycled plastic, waste tyres, recycled glass and date palm in mortar or concrete are few examples [1]-[6]. 
Rice husk is one of the agricultural wastes that is used as a major source of biomass for fuel generation. Rice husks are usually dumped in the open area, thas is leading to contamination of water and consumption of huge land space, thereby impacting the environment negatively without any economic benefits. After the combustion of rice husk, ash is produced known as rice husk ash (RHA). When rice husk is incinerated, it produces $17 \%-20 \%$ mass of RHA out of the initial mass, that is a lightweight, bulky, and highly porous material with a density of around 180-200 kg/m ${ }^{3}$ [7]-[9]. RHA had been one of the wastes that has such excellent pozzolanic characteristics due to its high silica content [10]. The percentage of silica $\left(\mathrm{SiO}_{2}\right)$ and the carbon contents in the ash range between $80 \%-90 \%$ and $30 \%-50 \%$ respectively [11].

RHA is thicker as compared to the interior surface, and there is an interlayer that consists of a crisscross mesh of chips between the two surfaces. The chips are arranged in loose honeycombed fashion and contain a large number of holes. Many nanosized pores ranging from several nanometers to several microns are distributed in the interlayer. These pores contribute to the huge specific surface area and high reactivity of RHA when it is ground to powder. RHA is a fine material with particle sizes being generally less than $45 \mu \mathrm{m}$ and the average particle size being in the range of 6-10 $\mu \mathrm{m}$ [4]. A. Siddika et al. [12] investigated that RHA is suitable as an additional cementitious material, which can be obtained by controlled or natural incineration and used with or without further processing. They have further revealed that the increase of cement replacement with RHA results in decreasing the slump and increasing the water demand.

Most studies [7], [13] have focused on the partial replacement of cement particles with RHA. S. Mayooran et al. [10] reported that the use of rice husk ash at levels of up to 5\% as a replacement of cement could improve the mechanical properties of concrete. M. Jamil et al. [14] found that when RHA is applied in the preparation of mortar specimens, the compressive strength of mortar significantly increases due to the filler and pozzolanic actions. However, a lower contribution pozzolanic reaction of RHA to the strength development of mortar is observed at early ages ( 7 and 14 days). Pozzolanic reactions of RHA depend on their particle size, ageing time and percentage replacement of cement. S.K. Tulashie et al. [15] discussed encouraging the cement and construction industries to partially replace ordinary Portland cement with RHA to enhance the compressive strength of mortar structures. Practically, even in countries with a limited production, RHA can be a valuable addition in special products such as high strength concrete and repair mortars and also RHA addition in concrete is feasible since slump can be retained at target with the small addition of a superplasticizer, strength profile remains competitive [16].

The studies focused on thermal properties of RHA mixed mortars have been very limited. Therefore, the current study aims to investigate the thermal and mechanical properties of mortar containing various amounts of rice husk ash.

\section{Experimental program}

\subsection{Materials}

Ordinary portland cement and well-graded river sand with the size range of $0.251 .18 \mathrm{~mm}$ were used in all the mortar mixtures. RHA used in this study (Fig. 1) was obtained from a factory in the northwestern part of Sri Lanka which has a tropical environment. According to Fig. 2 most pozzolanic particles present in between 10-50 $\mu \mathrm{m}$. Here, the RHA with particle size less than $75 \mu \mathrm{m}$ was used for this test program. The grading curve obtained as a result of 
the Laser Diffraction analysis. The nature of RHA particles and their size distribution were observed by scanning electron microscopes (SEM) shown in Fig. 3. These SEM images showed that most of RHA have planar and angular shapes with ample smooth surface texture. The chemical composition was analysed by Atomic absorption spectroscopy and results are presented in Table 1. As shown in Table 1, RHA was mainly composed of silica along with major oxides of potassium, calcium and magnesium. Similar observations were reported in previous studies [17].
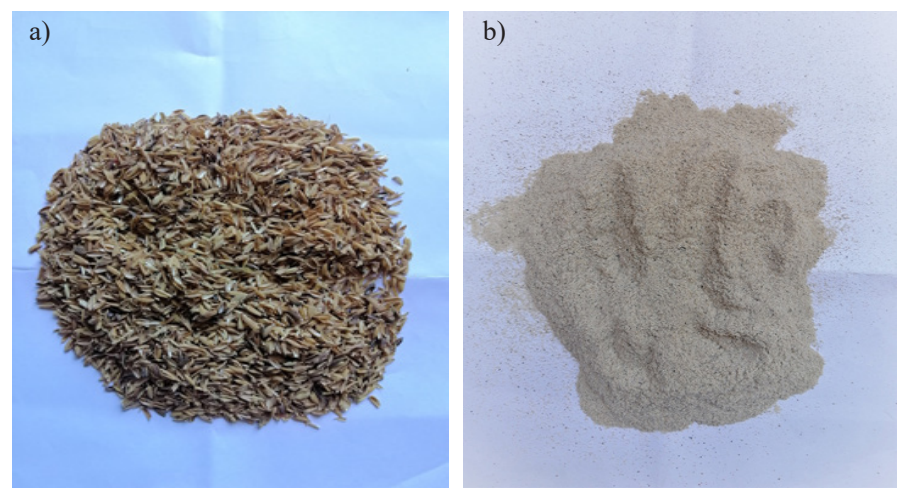

Fig. 1. Illustration of: a) rice husk, b) rice husk ash used for the experimental program. Source: own study

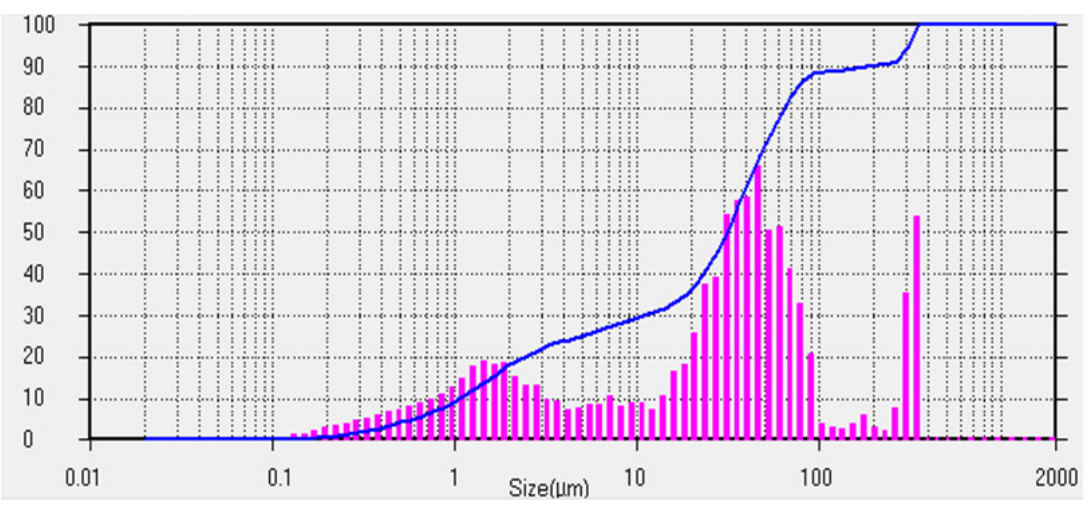

Fig. 2. The Particle size distribution of RHA obtained by Laser Diffraction analysis. Source: own study
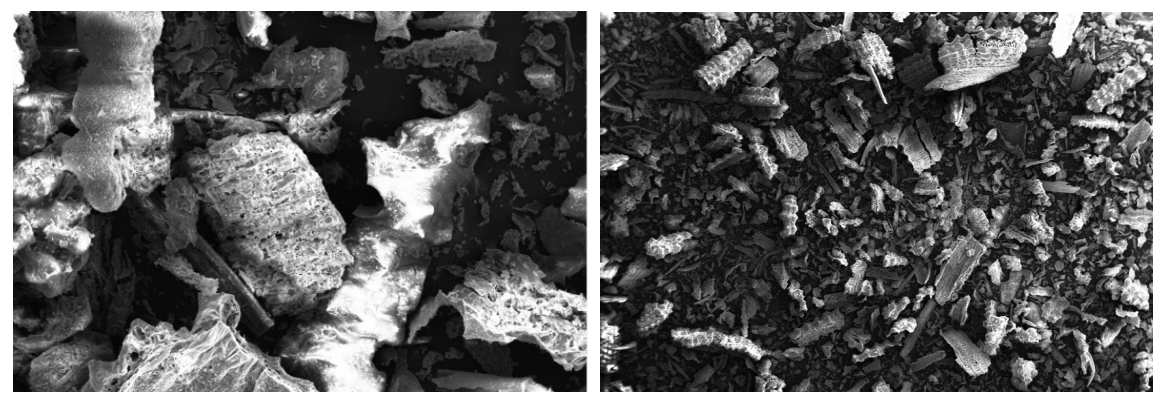

a)

b)

Fig. 3. SEM observation of RHA: a) at $\times 75$, b) at $\times 500$ magnification level. Source: own study 
Table 1. Chemical examination of RHA. Source: own study

\begin{tabular}{lllllllll}
\hline $\begin{array}{l}\text { Chemical } \\
\text { composition }\end{array}$ & $\mathrm{SiO}_{2}$ & $\mathrm{Al}_{2} \mathrm{O}_{3}$ & $\mathrm{CaO}$ & $\mathrm{Fe}_{2} \mathrm{O}_{3}$ & $\mathrm{MgO}$ & $\mathrm{Na}_{2} \mathrm{O}$ & $\mathrm{K}_{2} \mathrm{O}$ & LOI \\
\hline$\%$ & 85.4 & 1.1 & 2.6 & 0.7 & 1.4 & 0.8 & 3.4 & 7.9 \\
\hline
\end{tabular}

\subsection{Sample preparation}

The control mortar mixes were prepared by using cement: sand mass ratio of 1:3. Mortar specimens with RHA were prepared using constant and varying water-cement ratios. Initially, the water-cement ratio was 0.5 . The details of the specimens are given in Table 2. The flowability of mortar was measured according to ASTM C1437 [18]. The average flow diameter of the control mixture without RHA was $140 \mathrm{~mm}$. Since the workability of mortar mixture decreases with the addition of RHA, a constant flow $(140 \mathrm{~mm})$ was maintained by varying $\mathrm{w} / \mathrm{c}$.

Table 2. Mix proportion of mortars. Source: own study

\begin{tabular}{llllll}
\hline Mix designation & RHA $(\%)$ & Cement $(\mathrm{kg})$ & Sand $(\mathrm{kg})$ & RHA $(\mathrm{kg})$ & Water $(\mathrm{kg})$ \\
\hline M0 & 0 & 1 & 3 & 0 & 0.50 \\
\hline M10 & 10 & 1 & 2.7 & 0.3 & 0.78 \\
\hline M20 & 20 & 1 & 2.4 & 0.6 & 0.92 \\
\hline M30 & 30 & 1 & 2.1 & 0.9 & 1.24 \\
\hline M50 & 50 & 1 & 1.5 & 1.5 & 1.96 \\
\hline M70 & 70 & 1 & 0.9 & 2.1 & 2.24 \\
\hline M80 & 80 & 1 & 0.6 & 2.4 & 2.68 \\
\hline M100 & 100 & 1 & 0 & 3 & 3.06 \\
\hline
\end{tabular}

\subsection{Testing and results}

In the application of buildings, it is important to ensure better thermal performance with the new product. Hence, the thermal conductivity of samples was measured. According to the mortar classification in ASTM C270 [19], the minimum requirement for average compressive strength for the general purpose at 28 days is $5.2 \mathrm{MPa}$. Therefore, compressive strength testing was also done in accordance with ASTM C109 [20].

\subsubsection{Thermal conductivity}

The specimens were prepared in circular shaped moulds with $60 \mathrm{~mm}$ diameter and $5 \mathrm{~mm}$ depth as shown in Fig. 4. After 28 days of curing in water, the specimens were tested based on the principle of the lee disc method [21] as shown in Fig. 5. A total of 24 samples were prepared.

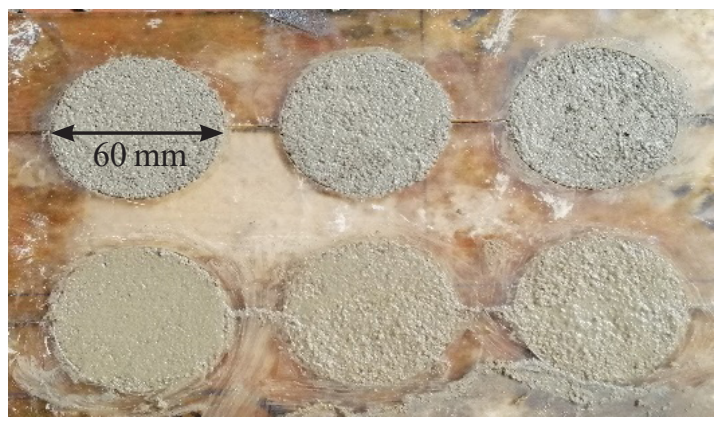

Fig. 4. Specimens to check thermal conductivity. Source: own study 


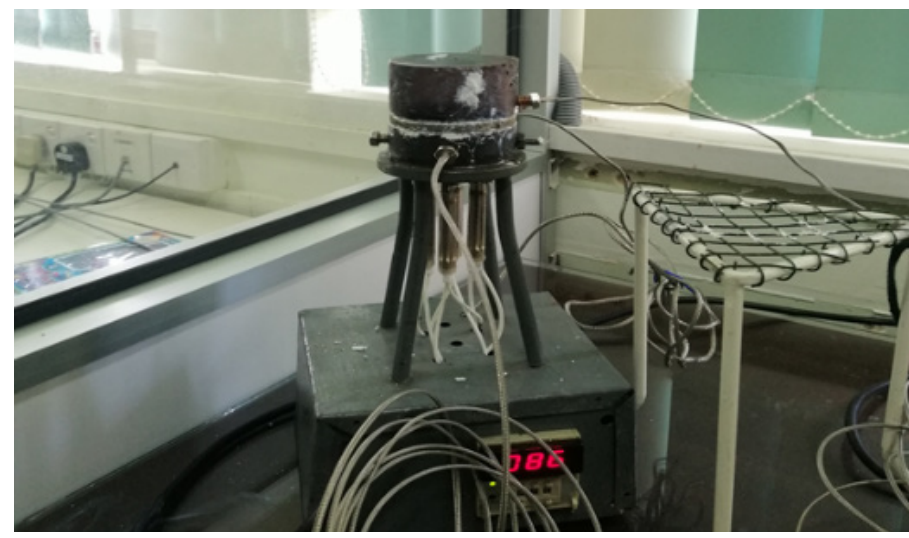

Fig. 5. Test set-up. Source: own study

Figure 6 shows the thermal conductivity of mortar with different levels of RHA replacement. It is noted that the addition of RHA into the mortar results in good thermal conductivity of the mortar which exhibited a good thermal insulation property. The thermal conductivity of the $100 \%$ RHA mortar was approximately $0.213 \mathrm{~W} / \mathrm{mK}$. This is $67.42 \%$ lower than the control mixture. The thermal conductivity of porous materials is governed by the voids in the sample [2]. Thus, mortar filled with $100 \%$ RHA results in an increase in the number of voids lead to lower conductivity of the final product.

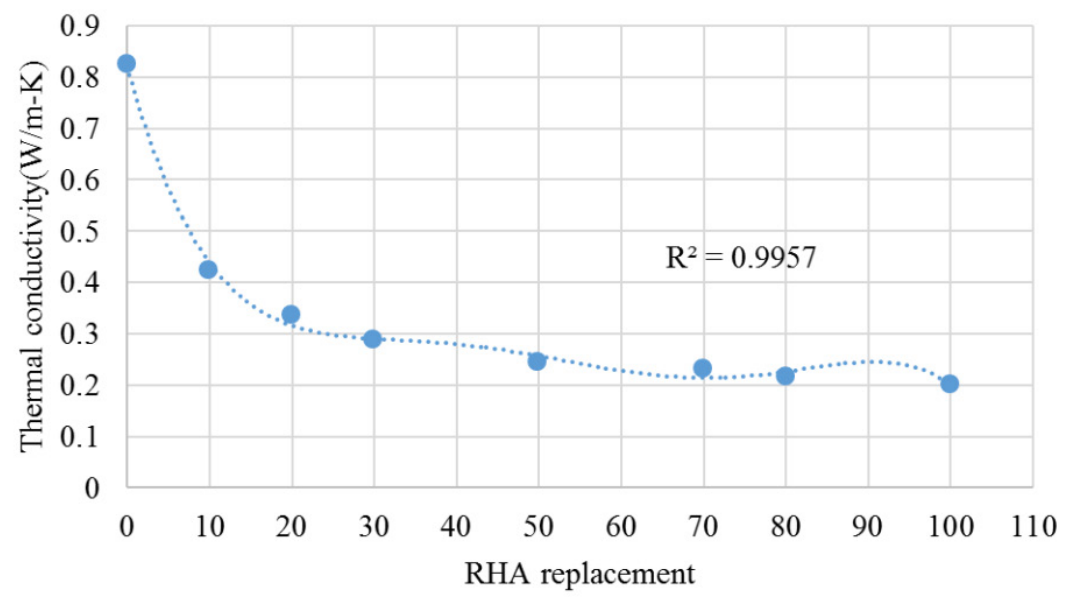

Fig. 6. Thermal conductivity variation with RHA replacement. Source: own study

The coefficient of determination (0.9957) shows a fairly good prediction for thermal conductivity.

\subsubsection{Compressive strength}

The preparation of the mixture is made by first mixing the materials cement, sand and RHA was mixed first without adding water when the mixture becomes homogeneous. Then, water is added to the mixture and mixed for $5 \mathrm{~min}$ in the mixing machine running with an 
angular velocity of $50 \mathrm{rpm}$. Compressive strength of mortar cube specimens as shown in Fig. $7(70 \times 70 \times 70 \mathrm{~mm})$ incorporating RHA were performed in accordance with ASTM C109 [18]. Cubes were cured and tested for compressive strength at 7 and 28 days. A total of 24 samples were prepared.

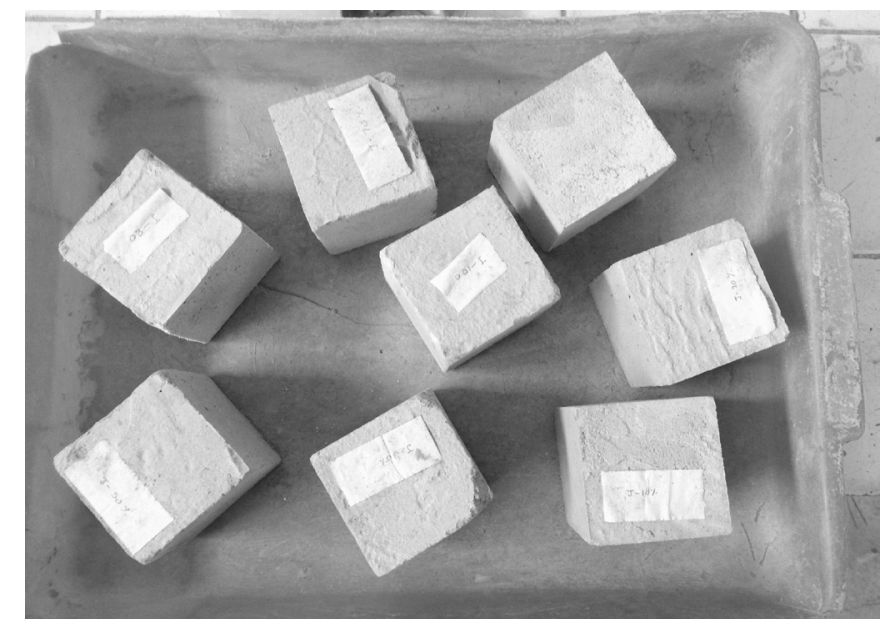

Fig. 7. Mortar cube specimens. Source: own study

Figure 8 shows the variation of the compressive strength of mortar as a function of RHA replacement at 7-days and 28-days of curing. It is noticed that the compressive strength of mortar decreases drastically with the increase of RHA. Mortar containing 10\% to 50\% RHA shows a considerable compressive strength, while the replacement of RHA above 50\% shows a negative impact on the compressive strength (Fig. 10). The average compressive strength of specimens with 50\% RHA replacement is $4.8 \mathrm{MPa}$, less than the minimum requirement for type $\mathrm{N}$ mortar [22]. This behaviour is due to the addition of low-density RHA which leads to an increase in porosity of mortars. A similar trend observed in previous studies [14], [22].

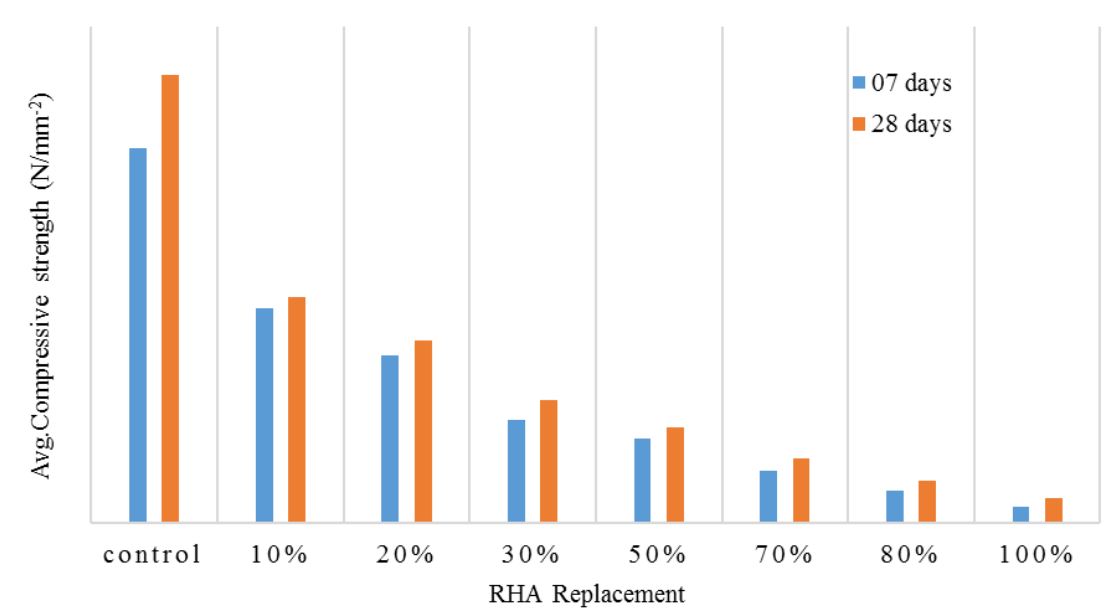

Fig. 8. Relationship between compressive strength and amount of RHA. Source: own study 


\subsubsection{Density}

The density of mortars with the variation of RHA replacement at 28 days also measured (Fig. 9). The result has shown that the density of samples with RHA was lower than that of control samples. Both bulk density and dry density have been decreased with the increase of RHA replacement. When the sand was entirely replaced with RHA, the dry density of mortar was $0.6 \mathrm{~g} / \mathrm{cm}^{3}$ whereas for control sample $2.2 \mathrm{~g} / \mathrm{cm}^{3}$ at the age of 28 days. This is due to the replacement of high-density sand with low-density RHA and also mortars containing RHA absorb more water which forms internal voids in mortars.

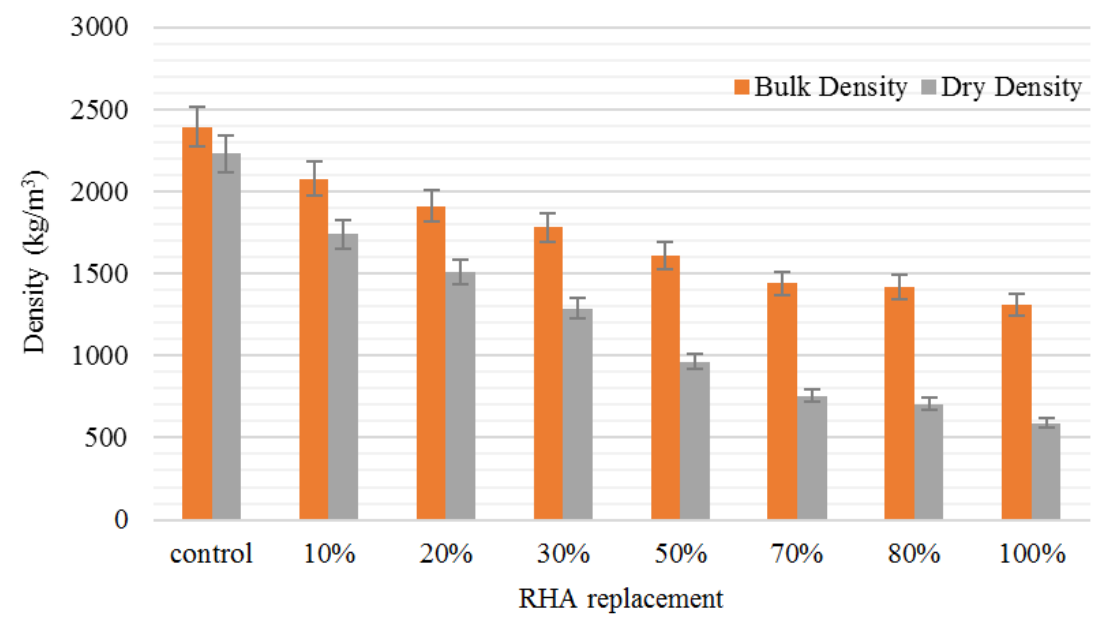

Fig. 9. Relationship between density and percentage of RHA. Source: own study

\subsubsection{Microstructure examination}

Pure RHA and mortar specimens containing a various proportion of RHA tested for thermal conductivity were observed by SEM.

The microstructure of mortars containing 10, 20, 30, 50, 70 and 100\% of RHA was examined using a Scanning Electron Microscope (SEM). Figure 10 shows the SEM image of control mortar without RHA. Fig. 11 shows the results of SEM analysis for different percentages of RHA replacement. According to the figures, the size and density of voids had increased with the increase of RHA. This can be explained by the excess water absorbed by the RHA and has resulted in a reduction of compressive strength.

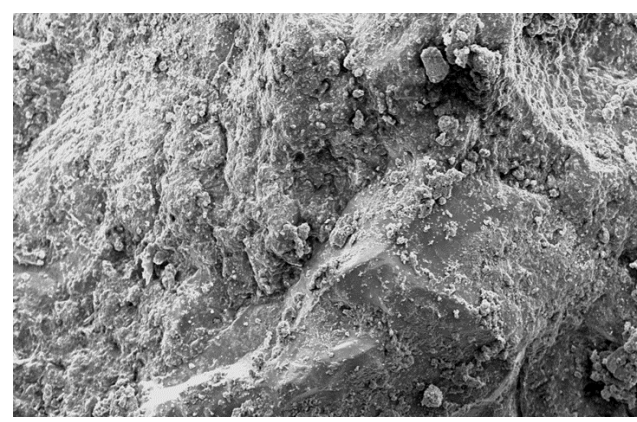

Fig. 10. SEM image of mortar without RHA. Source: own study 

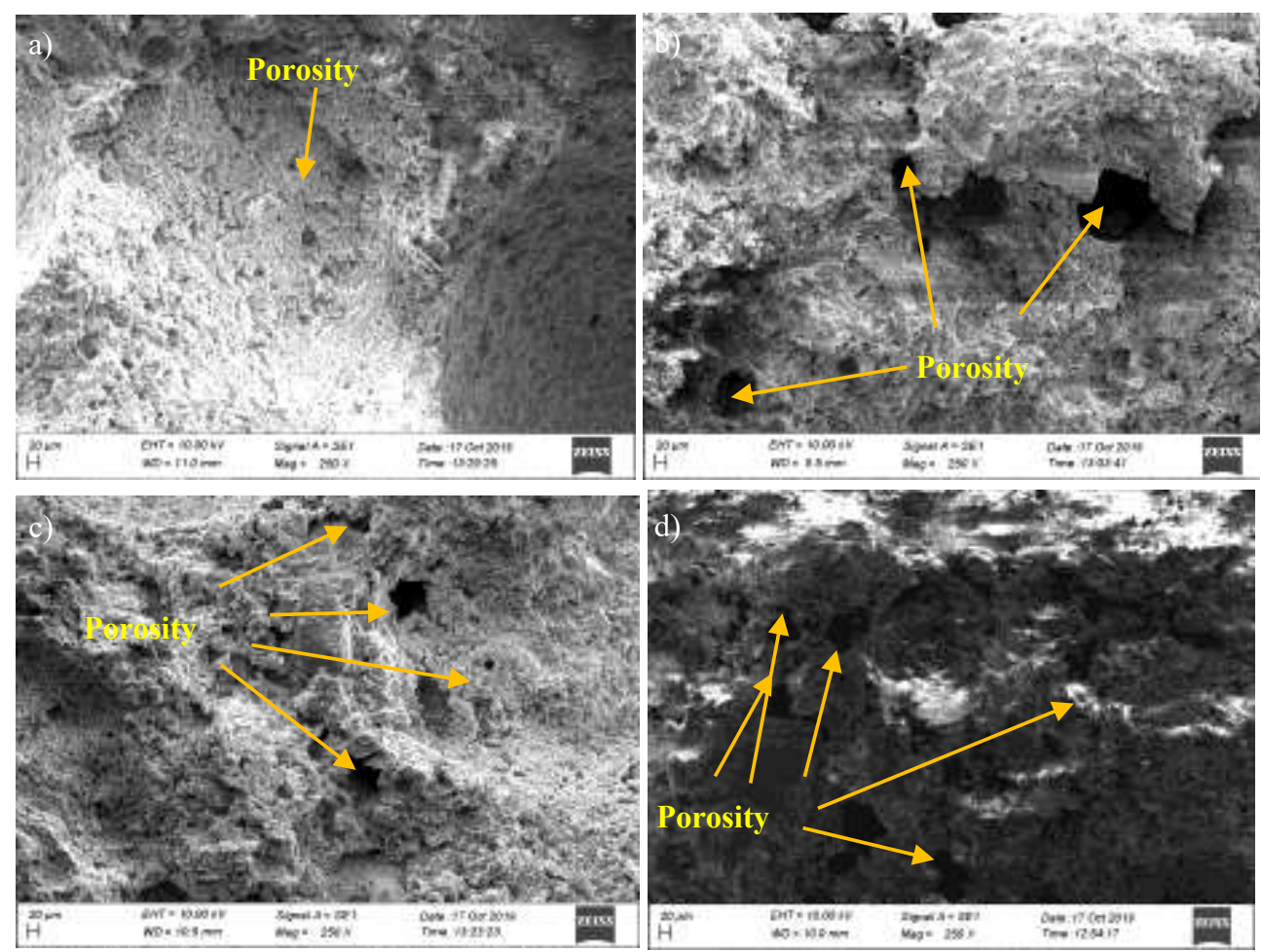

Fig. 11. SEM images of mortar shows the pores in mortar containing, a) $20 \%$, b) $30 \%$, c) $50 \%$, d) $100 \%$ rice husk ash. Source: own study

\section{Conclusion}

This study was focused on the development of an innovation of low cost insulated mortar rice waste result from paddy cultivation. The following conclusion can be made:

1. The composition RHA result from tropical cultivation is also very similar to other parts of the world.

2. The density of mortar with RHA decreases with increase in the percentage of RHA replacement. A reduction of $32.7 \%$ of bulk density was noted with the $50 \%$ replacement of RHA.

3. Almost a similar reduction in thermal conductivity was noted when the replacement ratio of RHA exceeds $50 \%$. This is about $78.3 \%$ reduction when compared to cementitious mortar.

4. SEM results indicate an increase in porosity of mortar with the increase of RHA replacement. This has caused the heavy reduction in compressive strength of RHA replaced mortar when the replacement ratio exceeds $50 \%$.

\section{References}

[1] Mandal A.K., Verma H.R., and Sinha O.P., "Utilization of aluminum plant's waste for production of insulation bricks", J. Clean. Prod., vol. 162, 2017, pp. 949-957. 
[2] Torkittikul P., Nochaiya T., and Wongkeo W., "Utilization of coal bottom ash to improve thermal insulation of construction material", J. Mater. Cycles Waste Manag., 2015.

[3] Abu Bakar B.H., Ramadhansyah P.J., and Megat Azmi M.J., "Effect of rice husk ash fineness on the chemical and physical properties of concrete", Mag. Concr. Res., vol. 63, no. 5, 2011, pp. 313-320.

[4] Jaya R.P. et al., "Physical and chemical properties of cement with nano black rice husk ash", in AIP Conference Proceedings, 2019, vol. 2151.

[5] Corinaldesi V., Mazzoli A., and Moriconi G., "Mechanical behaviour and thermal conductivity of mortars containing waste rubber particles". Mater. Des., vol. 32, no. 3, 2011, pp. 1646-1650.

[6] Kapur P.C., "Thermal Insulations from Rice Husk Ash, an Agricultural Waste", Ceramurgia International, vol. 6, 1953, pp. 75-78. https://doi.org/10.1016/0390-5519(80)90045-9

[7] Patel J.S., Parikh K.B., and Darji P.A.R., "Study on Concrete Using Fly Ash, Rice Husk Ash and Egg Shell Powder", International Journal for Research, vol. 5, 2017, pp. 566-570.

[8] Musa M.N., Fikhri M., and Aziz A., "Thermal Conductivity for Mixture of Rice Husk Fiber and Gypsum", Applied Mechanics and Materials, vol. 819, 2016, pp. 69-73. https://doi.org/10.4028/ www.scientific.net/AMM.819.69

[9] Ruiz-herrero J.L. et al., "Mechanical and thermal performance of concrete and mortar cellular materials containing plastic waste", Construction and Building Materials, vol. 104, 2016, pp. 298-310. https://doi.org/10.1016/j.conbuildmat.2015.12.005

[10] Mayooran S., Ragavan S., and Sathiparan N., "Comparative study on open air burnt low- and high-carbon rice husk ash as partial cement replacement in cement block production", J. Build. Eng., vol. 13, (May 2017), pp. 137-145. https://doi.org/10.1016/j.jobe.2017.07.011

[11] Prasara-a J. and Gheewala S.H., "SC," J. Clean. Prod., 2016.

[12] Siddika A., Al Mamun A., and Ali H., "Study on concrete with rice husk ash," Innov. Infrastruct. Solut., vol. 3, no. 3, 2018. https://doi.org/10.1007/s41062-018-0127-6

[13] International T. and Of J., "Experimental Study on Rice Husk as Fine Aggregates in Concrete", no. 1992, 2014, pp. 9-14.

[14] Jamil M., M. Khan N.N., Karim M.R., Kaish A.B.M.A., and Zain M.F.M., "Physical and chemical contributions of Rice Husk Ash on the properties of mortar", Constr. Build. Mater., vol. 128, 2016, pp. 185-198.

[15] Kofi S., Kotoka F., Mensah D., and Kwame A., "Investigation of the compressive strength of pit sand, and sea sand mortar prisms produced with rice husk ash as additives", Constr. Build. Mater., vol. 151, 2017, pp. 383-387. https://doi.org/10.1016/j.conbuildmat.2017.06.082

[16] Antiohos S.K., Papadakis V.G., and Tsimas S., "Cement and Concrete Research Rice Husk Ash (RHA) Effectiveness in Cement and Concrete as a Function of Reactive Silica and Fineness", Cem. Concr. Res., vol. 61-62, 2014, pp. 20-27. https://doi.org/10.1016/j.cemconres.2014.04.001

[17] Gonçalves M.R.F. and Bergmann C.P., "Thermal insulators made with rice husk ashes: Production and correlation between properties and microstructure", Construction and Building Materials, vol. 21, 2007, pp. 2059-2065. https://doi.org/10.1016/j.conbuildmat.2006.05.057

[18] ASTM C 1437-07, "Standard Test Method for Flow of Hydraulic Cement Mortar", Annu. B. ASTM Stand., 2009, pp. 6-7.

[19] ASTM C 270-07, "Standard Specification for Mortar for Unit Masonry", United States Am. Soc. Test. Mater., 2007, pp. 2-13.

[20] ASTM Committee, "ASTM C109/C109M-02 Standard Test Method for Compressive Strength of Hydraulic Cement Mortars," Annu. B. ASTM Stand., vol. 4, 2002, pp. 1-6.

[21] Piela L.B.D.C.L., "LEED v 4 for BD and C”, 2016, pp. 113-165.

[22] Na O. and Xi Y., "Mechanical and durability properties of insulation mortar with rubber powder from waste tires", J. Mater. Cycles Waste Manag., 2016. 
